\title{
Quality Outcomes in the Surgical Intensive Care Unit after Electronic Health Record Implementation
}

V. H. Flatow; N. Ibragimova; C. M. Divino; D. S. A. Eshak; B. C. Twohig; A. M. Bassily-Marcus; R. Kohli-Seth

Department of Surgery, Icahn School of Medicine at Mount Sinai, New York, NY, United States

\section{Keywords}

Electronic health records, quality improvement, critical care, surgical intensive care

\section{Summary}

Background: The electronic health record (EHR) is increasingly viewed as a means to provide more coordinated, patient-centered care. Few studies consider the impact of EHRs on quality of care in the intensive care unit (ICU) setting.

Objectives: To evaluate key quality measures of a surgical intensive care unit (SICU) following implementation of the Epic EHR system in a tertiary hospital.

Methods: A retrospective chart review was undertaken to record quality indicators for all patients admitted to the SICU two years before and two years after EHR implementation. Data from the twelve-month period of transition to EHR was excluded. We collected length of stay, mortality, central line associated blood stream infection (CLABSI) rates, Clostridium difficile (C. diff.) colitis rates, readmission rates, and number of coded diagnoses. To control for variation in the patient population over time, the case mix indexes (CMIs) and APACHE II scores were also analyzed. Results: There was no significant difference in length of stay, C. diff. colitis, readmission rates, or case mix index before and after EHR. After EHR implementation, the rate of central line blood stream infection (CLABSI) per 1000 catheter days was $85 \%$ lower $(2.16$ vs $0.39 ; \mathrm{RR}, 0.18 ; 95 \% \mathrm{Cl}$, 0.05 to $0.61, \mathrm{p}<.005)$, and SICU mortality was $28 \%$ lower ( 12.2 vs $8.8 ; \mathrm{RR}, 1.35 ; 95 \% \mathrm{Cl}, 1.06$ to $1.71, p<.01)$. Moreover, after EHR there was a significant increase in the average number of coded diagnoses from 17.8 to $20.8(p<.000)$.

Conclusions: EHR implementation was statistically associated with reductions in CLABSI rates and SICU mortality. The EHR had an integral role in ongoing quality improvement endeavors which may explain the changes in CLABSI and mortality, and this invites further study of the impact of EHRs on quality of care in the ICU.

\section{Correspondence to:}

Roopa Kohli-Seth, MD

1468 Madison Avenue

New York, NY 10029

Email: roopa.kohli-seth@mountsinai.org
Appl Clin Inform 2015; 6: 611-618

http://dx.doi.org/10.4338/ACl-2015-04-RA-0044

received: April 28, 2015

accepted in revised form: May 26, 2015

published: October 7, 2015

Citation: Flatow VH, Ibragimova N, Divino CM, Eshak DSA, Twohig BC, Bassily-Marcus AD, Kohli-Seth R. Quality Outcomes in the Surgical Intensive Care Unit After Electronic Health Record Implementation. Appl Clin Inform 2015; 6: 611-618

http://dx.doi.org/10.4338/ACI-2015-04-RA-0044 


\section{Introduction}

The United States spends more money per capita on health care than any other developed nation [1]. Despite this exorbitant spending, many patients still do not receive quality care [2]. It is commonly believed that health information technology (IT), and in particular the electronic health record (EHR), improves both quality and cost effectiveness of medical care. As such, there is enormous governmental and private investment in EHR technology. The Health Information Technology for Economic and Clinical Health Act (2009) allocated 27 billion dollars in incentive payments to encourage care providers to use EHRs [3]. Many major medical centers have also spent hundreds of millions of dollars transitioning to EHRs [4]. However, there is a paucity of evidence that EHR investments improve patient outcomes or reduce healthcare spending.

EHR systems tend to run on inflexible isolated platforms incompatible with each other, posing particular integration challenges. This creates inefficiency in the exchange of health information among providers and hospitals, and makes it difficult and expensive to change from one EHR to another. As a consequence, competition between EHR systems is stifled with only a small number of companies making up the majority of the market [5]. This is a stark contrast from personal computers, where consumers can freely transfer their data among different operating systems. The lack of fluidity in the current EHR market can create barriers to patient care. To justify these barriers, EHRs must demonstrate their efficacy. Given the growing importance of health IT, rigorous research investigating EHRs is needed. EHRs must be continuously evaluated for their role in improving quality patient care.

According to the Institute of Medicine, an EHR must record and store patient information, be searchable, execute patient care orders, and aid in clinical decision-making [6]. EHRs can be considered good investments if they either save money or help improve patient health outcomes. EHRs may save money by increasing administrative efficiency and thus reducing administrative costs. However, highly computerized medical centers report similar administrative costs as less computerized centers [7]. The potential administrative efficiencies brought by EHRs are not guaranteed, and thus they alone do not justify the use of EHRs. The impetus for EHRs is usually cited as the potential for improved patient health outcomes and quality of care. Furthermore, improved patient health can theoretically reduce costs to society at large if disease sequelae are prevented.

Consequently, the majority of studies evaluating EHRs have looked at their ability to improve quality of care. Despite this aim, empiric benefit to EHR use has not been demonstrated extensively $[8,9,10]$. Some argue that many available EHR systems are fundamentally flawed and will be unable to realize the potential of health IT [5]. Others suggest that existing literature has not accurately evaluated EHRs' utility [11]. Still others posit that the problem does not lie with the systems themselves but rather with the way they are used [11]. Two large cross-sectional studies on thousands of non-federally funded office based practices did not find an association between EHR use and quality of care $[8,9]$. These studies measured physician adherence to recommended practice standards. On the other hand, positive effects of EHR use have been shown in specific clinical settings with the strongest evidence found in diabetes care $[12,13,14]$. Another major area of research has compared EHR systems with and without specific clinical decision support systems (CDSS) [15]. CDSSs use computer algorithms to provide patient specific care recommendations and have been shown to reduce nosocomial complications $[15,16]$. The most common quality improvement was aiding the therapeutic dosing of various medications. However, CDSS's impact on patient health or cost effectiveness remains unclear [15]. Several studies have evaluated the use and safety of computerized physician order entry (CPOE) systems. Prior data suggests that CPOE decreases medication errors in the intensive care unit (ICU) setting, but there is mixed data on the effect of EHRs on ICU mortality $[17,18]$. CPOE systems were reported to increase mortality in pediatric intensive care units, while others found no association [17, 18]. These large cross sectional studies may be confounded by variations in patient populations and variations in the use of EHRs across practices. Therefore, impact of EHRs on ICU is not yet clear. 


\section{Objectives}

To evaluate key quality of care indicators before and after implementation of an EHR, performing a retrospective cohort study in a surgical intensive care unit (SICU), where efficient quality control is mandatory for the extensive resource demands.

\section{Methods}

A retrospective chart review was conducted to record the quality indicators for all patients admitted to the SICU between Jan 1, 2009 and Dec 31, 2013 (3742 patients). Quality indicators were evaluated for all patients admitted to the SICU two years before (January 1, 2009 to December 31, 2010, n $=1274$ ) and two years after (January 1, 2012 to December 31, 2013, n = 1229) EHR implementation. Data from the twelve-month period during the transition to EHR was excluded in order to minimize the confounding effect that transitioning to a new technology may have had on quality of care in the SICU (December 31, 2010 to January 1, 2012). We specifically focused on the SICU at Mount Sinai Hospital during hospital-wide implementation of the Epic EHR system. The SICU produces some of the most costly medical care in the hospital. SICU resource demands are so extensive that an effective hospital-wide EHR should especially target the quality of care in the SICU - for example, from EHR-generated algorithms, decision-aides, and safety initiatives (e.g. a "stop" for drug interactions). The Institutional Review Board provided a waiver of consent to access patient information for analysis. The Surgical Intensive Care Unit (SICU) is a 14-bed unit in a large tertiary teaching hospital. There are approximately 750 admissions per year. The unit is closed and all care is directed by an ICU team which includes an attending intensivist, critical care fellows, surgery and anesthesiology residents, physician assistants, nurse practitioners and bedside nurses. Post-operative care is managed for patients from a variety of surgical subspecialties, including general surgery, solid organ transplant, and surgical oncology. We collected data on length of stay (LOS), mortality, central line associated blood stream infection (CLABSI) rates, Clostridium difficile (C. diff) colitis rates, readmission rates, and the number of coded diagnoses. CLABSI was reported as rate per 1000 device days. C. diff was calculated per 10000 patient days. Readmissions were calculated as total readmissions during a single patient admission. To control for variation in the patient population over time, the case mix indexes (CMIs) and APACHE II were also analyzed. Data on APACHE II scores were utilized from an ongoing PI project that collected data on all SICU patients who expired or were readmitted within 48 hours during our study period. The data was analyzed to calculate the correlation between treatment group (pre vs. post-EHR) and each of the health outcomes using the chi-square test or independent samples t-tests in IBM's SPSS Statistics. A p-value of less than .05 was considered significant.

\section{Results}

There was no significant difference in length of stay, $C$. diff colitis, readmission rate, or case mix indexes before and after EHR. The rate of CLABSIs per 1000 catheter days was lower after EHR implementation (2.16 vs 0.39; Relative Risk [RR], 0.18; 95\% Confidence Interval [CI], 0.05 to 0.61, $\mathrm{p}<.005)$. SICU mortality also significantly decreased after EHR use (12.2 vs 8.8; RR, 1.35; 95\% CI, 1.06 to $1.71, \mathrm{p}<.01)$. There was a significant increase in the average number of coded diagnoses after EHR from 17.8 to 20.7 ( $\mathrm{p}<.000,95 \%$ CI, 1.06 to 1.71) and in the APACHE II scores from 15.7 to 18.4 ( $\mathrm{p}<.000,95 \% \mathrm{CI}, 1.39$ to 3.95$)$.

\section{Discussion}

To our knowledge, this is the only study that reports a significant association of EHR implementation with lower ICU mortality and CLABSI rates. While several studies have investigated various aspects of EHRs, few studies demonstrate the role of EHRs on patient outcomes, and these few 
studies tend to focus on outpatient care $[8,9,12,13,17,19,20]$. In our study, CMIs did not change, suggesting that case complexity in the SICU was constant. There was some increase in APACHE II scores which may be attributable to the easier ability to accurately calculate them with the EHR. It is important that CMI and APACHE II did not change dramatically, because this decreases confounding effects of population changes over time. The number of coded diagnoses increased, and this was most likely due to the relative ease of adding coded diagnoses into the EHR.

There was no change in length of stay after EHR. However, SICU LOS is already low at baseline, making it less likely to show a significant difference. Rates of 48-hour readmissions were unchanged, with overall incidence very low. To our knowledge there is no prior research investigating 48-hour readmission after EHR. Rates of $C$. diff infections were also unchanged. Current studies suggest the use of EHR-based detection of risk factors for C. diff infections relapse [21].

CLABSI rates significantly decreased by $82 \%$. In May of 2012 the SICU implemented an EHRbased daily goals sheet with five top priorities to be addressed by all members of the care team. One top priority is a daily order for central line necessity, and a requirement to justify the continued use of a central line each day. This expedites removal of central lines when they are no longer are required, thereby decreasing the likelihood of infection. Daily goals sheets can increase nurses' identification of patient goals from $10 \%$ to $95 \%$ [22]. Though daily goals sheets can be implemented without EHR, EHRs serve as a powerful reminder to complete them. Daily goal sheets outside of EHR were used in the SICU beginning in January of 2010. Despite being used for 12 months during our pre-study period, CLABSI infections still improved after EHR implementation. SICUs are constantly undergoing quality improvement procedures. Any study investigating EHR in absence of these ongoing measures would be near impossible. Nevertheless, this is an important confounder of our study. EHRs help standardize patient records, allowing them to be better understood by the numerous providers on the care team. At Mount Sinai Hospital, the EHR automatically emails the unit leadership-director, nurse manager, and nurse coordinator at $9 \mathrm{AM}$ every day of the positive blood cultures from the day before. The unit leadership does a mini root cause analysis the same day. This mechanism allows for immediate intervention in patient management as well as linking and documenting infections to a specific source. Greater efficiency in tracking and reporting infections allowed the SICU to better implement infection control efforts. Several studies have also found that reliable computer algorithms can be used in EHRs to monitor CLABSI infections [23]. Expedited culture results act as an aid in physician decision-making. The literature shows that other physician decision aids, such as clinical decision support systems, are able to reduce rates of pulmonary embolism and deep vein thrombosis by identifying patients at risk [16].

Mortality in the SICU decreased by $28 \%$ after EHR implementation. This mortality decrease may be partially attributable to a decrease in CLABSI infections or to changes in sepsis management. One of the strongest determinants of survival from sepsis is the time between hypotension and the initiation of antibiotics [24]. After EHR implementation, the increased efficiency in reporting blood stream infections in real time has helped decrease the time to antibiotic administration in sepsis. Our findings are consistent with prior research that found decreases in mortality and complications after computerization of patient records across multiple medical centers [25]. Previous data suggests that CPOE decreases medication errors in adult, pediatric and neonatal intensive care units $[17,19]$. Mount Sinai Hospital's EHR has automatic flags prohibiting medication orders if they pose a heightened risk for drug interactions, allergies, or dosing or frequency errors. In addition to protecting from medication errors, EHRs decrease turnaround time between medication orders and administration [19].

Quality improvement (QI) initiatives in the SICU were implemented concurrently with the EHR. One improvement for the SICU was the hiring of more physician extenders, such as physician assistants and nurse practitioners, in October 2012. A second improvement is a palliative care consultation initiative implemented in September 2013 to ensure early involvement of palliative care. This has helped to promote early discussions about long-term expectations and goals of care as soon as a patient meets any "trigger" criteria which are screened for with data from the EHR ( Table 2). When appropriate, patients are transferred to hospice reducing hospital and SICU mortality. However, an ongoing study at Mount Sinai investigating the effect of palliative care triggers on SICU and hospital mortality did not reach statistical significance. Palliative care triggers were also a medical board initiative in the SICU and showed improvement in patient centered outcomes but failed to 
demonstrate an improvement in mortality. Changes in mortality during the study period may be attributable to the ongoing QI efforts in the SICU. It's important to recognize the vital, integrated role of the EHR in each of these QI endeavors.

The impact on quality outcomes after EHR implementation compels consideration of cost effectiveness. In our study, increased coded diagnoses and lower mortality rates contribute to an overall lower adjusted mortality rating, which increases outcome-weighted reimbursements. A diminished rate of CLABSI infections also contributes to cost savings. The average cost of care for a CLABSI infected patient is $\$ 45000$ [26]. Our study suggests concrete economic benefits after EHR implementation.

\section{Conclusion}

The changing landscape of healthcare mandates rigorous research on health information technology. In our study, EHR implementation was statistically associated with lower CLABSI and SICU mortality. However, several QI initiatives geared towards reducing CLABSIs and mortality in the SICU were implemented concurrently with the EHR. Nevertheless, the EHR had an integral role in these ongoing QI initiatives, which may explain the improved quality of care in the SICU after EHR implementation. This warrants further investigation to better understand how EHRs effect quality of care, and to better elucidate EHR cost effectiveness.

\section{Clinical Relevance Statement}

Considering the large investment into electronic health records and the high costs associated with SICU care, it's important to develop EHRs that improve SICU quality of care.

\section{Conflict of Interest}

The authors of this study report no conflicts of interest.

\section{Protection of Human and Animal Subjects}

The study was performed in compliance with the World Medical Association Declaration of Helsinki on Ethical Principles for Medical Research Involving Human Subjects, and was reviewed by the Mount Sinai Hospital Institutional Review Board. 
Table 1 Patient Quality Outcomes Before and After EHR

\begin{tabular}{|c|c|c|c|c|}
\hline & Before EHR & After EHR & $\begin{array}{l}\text { Between Group } \\
\text { Comparisons }\end{array}$ & $P$ value \\
\hline Case Mix Index & $\begin{array}{l}6.15( \pm 4.79) \\
n=1128\end{array}$ & $\begin{array}{l}6.03( \pm 4.62) \\
n=1103\end{array}$ & NS & NS \# \\
\hline APACHE II Scores & $\begin{array}{l}15.73( \pm 4.52) \\
n=96\end{array}$ & $\begin{array}{l}18.40( \pm 4.78) \\
n=110\end{array}$ & 2.67 (1.39 to 3.95$)$ & $\mathrm{p}<.000$ \# \\
\hline Mortality in SICU & $\begin{array}{l}12.2 \% \\
n=155 / 1273\end{array}$ & $\begin{array}{l}8.8 \% \\
n=105 / 1198\end{array}$ & 1.35 (1.06 to 1.71$)$ & $p<.01^{\$}$ \\
\hline CLABSI* & $\begin{array}{l}2.16 \ddagger \\
n=18 / 8348 \dagger\end{array}$ & $\begin{array}{l}0.39 \ddagger \\
n=3 / 7689 \dagger\end{array}$ & $.18(.05$ to .61$)$ & $p<.005^{\$}$ \\
\hline C. diff. colitis & $\begin{array}{l}24.6^{* *} \\
n=23 / 9312\end{array}$ & $\begin{array}{l}26.4^{* *} \\
n=24 / 9051\end{array}$ & NS & $N S^{\$}$ \\
\hline $\begin{array}{l}\text { Length of Stay } \\
\text { (Number of days) }\end{array}$ & $\begin{array}{l}6.99 \\
n=1274\end{array}$ & $\begin{array}{l}6.76 \\
n=1229\end{array}$ & NS & NS \# \\
\hline $\begin{array}{l}\text { Number of Coded } \\
\text { Diagnoses }\end{array}$ & $\begin{array}{l}17.81( \pm 10.38) \\
n=1128\end{array}$ & $\begin{array}{l}20.73( \pm 11.55) \\
n=1103\end{array}$ & 2.98 (2.07 to 3.89$)$ & $\mathrm{p}<.000^{\#}$ \\
\hline $\begin{array}{l}\text { 48-Hour Readmis- } \\
\text { sion Rates }\end{array}$ & $\begin{array}{l}0.4 \% \\
n=5 / 1294\end{array}$ & $\begin{array}{l}0.08 \% \\
n=1 / 1237\end{array}$ & NS & NS $\$$ \\
\hline
\end{tabular}

* Lab confirmed blood infections (LCBI); ‡ Rate per 1,000 catheter days; † Number of catheter days; * ${ }^{*}$ Rate per 10000 patient days; \# Independent samples t-test; \$ Chi-square test

Table 2 SICU Palliative Care Triggers

\section{ELIGIBILITY CRITERIA}

One of the following must be present:

1. Stay in SICU greater than 7 days

2. Any repeat admission to the SICU during this hospitalization

3. Post cardiac arrest

4. Metastatic cancer or locally advanced lung, pancreatic, or head and neck cancer

5. Presence of two or more life-threatening co-morbidities:

- Severe brain injury: Glasgow Coma Scale $<9$ (off sedation),

- Hypotension requiring use of a vasopressor agent for $>12$ hours,

- End-stage renal disease: GFR $<30$,

- End-stage liver disease: $M E L D \geq 30$,

- Severe sepsis,

- Any active cancer, excluding non-melanoma skin cancer,

- Pre-existing tracheostomy, excluding head and neck cancer. 


\section{References}

1. Health expenditure, total (\% of GDP) [internet]. Washington (DC): The World Bank Group; 2015 [cited 2015 Mar 1]. Available from: <http://data.worldbank.org/indicator/ SH.XPD.TOTL.ZS?order=wbapi_data_value_2011+wbapi_data_value+wbapi_data_valuelast\&sort $=$ desc $>$.

2. McGlynn EA, Asch SM, Adams J, Keesey J, Hicks J, DeCristofaro A, Kerr EA. The Quality of Health Care Delivered to Adults in the United States. New Engl J Med 2003; 348: 2635-2645.

3. Blumenthal D, Tavenner M. The 'Meaningful Use' Regulation for Electronic Health Records. New Engl J Med 2010; 363: 501-504.

4. Moukheiber Z. The Staggering Cost Of An Epic Electronic Health Record Might Not Be Worth It. 2012 Jun 8 [cited 2015 Mar 31]. In: Forbes Business [Internet]. New York: Forbes. Available from: <http://www. forbes.com/sites/zinamoukheiber/2012/06/18/the-staggering-cost-of-an-epic-electronic-health-recordmight-not-be-worth-it/>.

5. Mandl, KD, Kohane, IS. Escaping the EHR Trap -The Future of Health IT. New Engl J Med 2012; 366: 2240-2242.

6. Institute of Medicine. Key Capabilities of an Electronic Health Record System: Letter Report. National Academies Press 2003.

7. Himmelstein DU, Wright A, Woolhandler S. Hospital computing and the costs and quality of care: a national study. Am J Med 2010; 123: 40-46.

8. Linder JA, Ma J, Bates DW, Middleton B, Stafford RS. Electronic health record use and the quality of ambulatory care in the United States. Archives of Internal Medicine 2007; 167: 1400-1405.

9. Romano MJ, Stafford RS. Electronic health records and clinical decision support systems: impact on national ambulatory care quality. Arch Intern Med 2011; 171: 897.

10. Keyhani S, Hebert PL, Ross JS, Federman A, Zhu CW, Siu AL. Electronic Health Record Components and the Quality of Care. Medical Care 2008; 46: 1267-1272.

11.Jones, SS, Heaton, PS, Rudin, RS, Schneider, EC. Unraveling the IT Productivity Paradox -Lessons for Health Care. New Engl J Med 2012; 366: 2243-2245.

12. Reed M, Huang J, Brand R, Graetz I, Neugebauer R, Fireman B, Jaffe M, Ballard DW, Hsu J. Implementation of an outpatient electronic health record and emergency department visits, hospitalizations, and office visits among patients with diabetes. JAMA 2013; 310: 1060-1065.

13. Cebul RD, Love TE, Jain AK, Hebert CJ. Electronic Health Records and Quality of Diabetes Care. New Engl J Med 2011; 365: 825-833.

14.Sankilampi U, Saari A, Laine T, Miettinen PJ, Dunkel L. Use of electronic health records for automated screening of growth disorders in primary care. JAMA 2013; 310: 1071-1072.

15. Garg AX, Adhikari NKJ, McDonald H. Effects of computerized clinical decision support systems on practitioner performance and patient outcomes. JAMA 2005; 293: 1223-1238.

16. Kucher N, Koo S, Quiroz R, Cooper JM, Paterno MD, Soukonnikov B, Goldhaber SZ. Electronic alerts to prevent venous thromboembolism among hospitalized patients. New Engl J Med 2005; 352: 969-977.

17. Beccaro MAD, Jeffries HE, Eisenberg MA, Harry ED. Computerized Provider Order Entry Implementation: No Association With Increased Mortality Rates in an Intensive Care Unit. Pediatrics 2006; 118: 290-295.

18.Han YY, Carcillo JA, Venkataraman ST, Clark RS, Watson RS, Nguyen TC, Bayir H, Orr RA. Unexpected Increased Mortality After Implementation of a Commercially Sold Computerized Physician Order Entry System. Pediatrics 2005; 116: 1506-1512.

19.van Rosse F, Rademaker CM, van Vught AJ, Egberts AC, Bollen CW. The effect of computerized physician order entry on medication prescription errors and clinical outcome in pediatric and intensive care: a systematic review. Pediatrics 2009; 123: 1184-1190.

20. Friedberg MW, Coltin KL, Safran DG, Dresser M, Zaslavsky AM, Schneider EC. Associations between structural capabilities of primary care practices and performance on selected quality measures. Annals of Internal Medicine 2009; 151: 456-463.

21. Hebert C, Du H, Peterson LR, Robicsek A. Electronic Health Record-Based Detection of Risk Factors for Clostridium difficile Infection Relapse. Infection Control and Hospital Epidemiology 2013; 34: 407-414.

22. Pronovost P, Berenholtz S, Dorman T, Lipsett PA, Simmonds T, Haraden C. Improving communication in the ICU using daily goals. Journal of Critical Care 2003; 18: 71-75.

23. Kahn KL, Weinberg DA, Leuschner KJ, Gall EM, Siegel S, Mendel P.The National Response for Preventing Healthcare-associated Infections: Data and Monitoring. Medical Care 2014; 52: S25-S32.

24. Kumar A, Roberts D, Wood KE, Light B, Parrillo JE, Sharma S, Suppes R, Feinstein D, Zanotti S, Taiberg L, Gurka D, Kumar A, Cheang M. Duration of hypotension before initiation of effective antimicrobial ther- 
apy is the critical determinant of survival in human septic shock. Critical care medicine 2006; 34: 1589-1596.

25. Amarasingham R, Plantinga L, Diener-West M, Gaskin DJ, Powe NR. Clinical information technologies and inpatient outcomes: A multiple hospital study. Arch Intern Med 2009; 169: 108-114.

26. O'Grady NP, Alexander M, Burns LA, Dellinger EP, Garland J, Heard SO, Lipsett PA, Masur H, Mermel LA, Pearson ML, Raad II, Randolph AG, Rupp ME, Saint S. Healthcare Infection Control Practices Advisory Committee (HICPAC). Guidelines for the prevention of intravascular catheter-related infections. Clinical infectious diseases 2011; 52(9): e162-e193. 